\title{
Journal of Inflammatory Bowel Diseases \& Disorders
}

\section{Pelvic Organ Prolapse (POP) Working Group (SICCR): Doubts and Evidence for a Practical Guide}

\author{
Filippo La Torre ${ }^{1 *}$, Filippo Pucciani ${ }^{2}$, Giuseppe Dodi ${ }^{3}$, Giuseppe Giuliani ${ }^{1}$, Alvise Frasson ${ }^{3}$, Diego Coletta ${ }^{1}$ and Peter Petros ${ }^{5}$ \\ ${ }^{1}$ Department of Surgery, Sapienza University, Rome, Italy \\ ${ }^{2}$ Department of Surgery and Translational Medicine, University of Florence, Italy \\ ${ }^{3}$ Department of Surgery, Oncology and Gastroenterology, University of Padova, Italy \\ ${ }^{4}$ University of NSW Professorial Department of Surgery, St Vincent's Hospital Sydney, Australia
}

*Corresponding author: Filippo La Torre, College of Medicine \& Odontoiatry, Sapienza University of Rome, 00161 Rome, Tel: 00390649970501; E-mail: filippo.latorre@uniroma1.it

Received date: November 18, 2016; Accepted date: December 12, 2016; Published date: December 19, 2016

Copyright: (c) 2016 Torre FL, et al. This is an open-access article distributed under the terms of the Creative Commons Attribution License, which permits unrestricted use, distribution, and reproduction in any medium, provided the original author and source are credited

\begin{abstract}
Pelvic Organ Prolapse (POP) can be defined as a downward descent of female pelvic organs, including the bladder, uterus, post-hysterectomy vaginal cuff and the small or large bowel, resulting in protrusion of the vaginal walls, uterus, or both. The International Continence Society includes also rectal prolapses. POP development is multifactorial.
\end{abstract}

Keywords Pelvic organ prolapse; Constipation; Fecal incontinence; Rectocele; Obstructed defecation; Pelvic surgery

\section{Introduction}

Pelvic Organ Prolapse (POP) can be defined as a downward descent of female pelvic organs, including the bladder, uterus, posthysterectomy vaginal cuff and the small or large bowel, resulting in protrusion of the vaginal walls, uterus, or both. The International Continence Society includes also rectal prolapses. POP development is multifactorial. Vaginal delivery, hysterectomy, chronic straining, normal ageing, and abnormalities of connective tissue or connectivetissue repair predispose some women to disruption, stretching, or dysfunction of the levatorani complex, connective-tissue attachments of the vagina, or both, resulting in prolapse. Patients generally present with several complaints, including bladder, bowel, and pelvic symptoms. No guidelines exist regarding the management of POP. The aim of working group, by means of consensus statement and literature review, is to give useful suggestions on clinical organization, diagnosis and treatment of POP.

\section{Methods}

To reach a consensus statement on the diagnosis and treatment of POP, the Italian Society of Colorectal Surgery (SICCR) nominated a pool of experts to constitute a committee. The members of the Committee were selected on the basis of their experience in treating functional pelvic floor disorders. The Committee developed a consensus on the diagnostic and therapeutic aspects of POP including a set of graded recommendations based on a review of the literature and, where present, on evidence-based medicine. A search of the literature was carried out using the online database of PUBMED, MEDLINE and COCHRANE to identify articles published in English before June 2015. This used specific keywords related to the different diagnostic tools, medical treatments and surgical techniques for POP. The recommendations of the Committee were graded on the base of the levels of evidence in accordance with the criteria of the Oxford Centre for Evidence-Based Medicine [1].

\section{Pelvic organ prolapse (POP): pathophysiology}

Schaffer et al. in 2005 identified vaginal delivery as the strongest risk factor for pelvic organ prolapse. The pathophysiological mechanisms of pelvic organ prolapse had not been fully elucidated, but it is likely that damaging or malfunctioning skeletal muscle, smooth muscle, connective tissue (Jelovseck et al.), and nerves (Krogh et al.) all play a role in the progression of this disease. Also ageing and chronically increased intra-abdominal pressure is believed to be a clinically relevant factor in the pathogenesis of prolapse [2]. The excess straining and associated perineal descent is thought to cause stretch injury to the pudendal nerve and result in neuropathy [3].

Strinic et al. in a prospective observational experimental study investigated matrix metalloproteinase-1 (MMP-1) and matrix metalloproteinase-2 (MMP-2) immune-histochemical expression in utero-sacral ligament biopsies from women with pelvic organ prolapse (POP) and controls with normal pelvic support. Data suggest that an increased MMP-1 immune-histochemical expression in utero-sacral ligaments is associated with urogenital prolapse [4].

Chen and Yeh reviewed the literature regarding collagen/elastin and extracellular matrix metabolism in the genitourinary tract, with special emphasis on stress urinary incontinence. Pelvic tissue from women with stress urinary incontinence and pelvic organ prolapse show a genetic predisposition to abnormal extracellular matrix remodeling, which is modulated by reproductive hormones, trauma, mechanical stress load and aging. This progressive remodeling contributes to stress urinary incontinence/pelvic organ prolapse by altering normal tissue architecture and mechanical properties [5]. Ward et al. published a review on genetic predisposition for pelvic organ prolapse. The metaanalysis suggested that collagen type 3 alpha 1 (COL3A1) rs1800255 genotype AA is associated with pelvic organ prolapse. An association with pelvic organ prolapse was seen in individual studies for estrogen receptor alpha (ER-a) rs2228480 GA, COL3A1 exon 31, chromosome 
9q21 as well as 6 single nucleotide polymorphisms identified by a genome-wide association study [6]. Allen-Brady et al. published a paper that showed the results of a genome wide linkage analysis to identify genes which predispose to pelvic organ prolapse (POP) using a resource of high-risk POP pedigrees. The linkage analysis showed evidence for significant genome-wide linkage on chromosome 10q24-26. Suggestive evidence was identified on chromosomes 6 and 17 , and an additional region on chromosome 10. In the subset of only the newly recruited familial POP cases, significant evidence for genome-wide linkage was observed on chromosome 17q25 and suggestive evidence for linkage was observed on chromosomes 10 and 11 .

In according with Petros ("The Integral Theory") $[7,8]$ POP and its symptoms such as urinary stress incontinence, urinary urge incontinence, abnormal bowel, bladder emptying, some forms of pelvic pain and fecal incontinence may be caused by laxity in the vagina or its supporting ligaments, as a result of altered connective tissue. The main etiologies were childbirth related laxity compounded by ageing.

Petros' theory hypothesizes that the vagina is suspended like a suspension bridge, with the ligaments above and the muscles below (Figure 1). The muscle forces (arrows) contract against the suspensory ligaments to give the bridge form and strength. Because the ligaments and vagina are the ultimate supports of the bladder and rectum, (Figures 1 and 2) anything which damages these structures can also affect the structure and function of bladder and rectum.

In accordance with this theory, if the suspensory ligaments are loose, the muscle strength weakens and the bladder and anorectum cannot be adequately closed and the patient can present with incontinence (urinary and/or faecal). The same damaged ligaments may not allow a different combination of muscles to open these same emptying tubes, so a patient may have to strain to empty her bladder or bowel, and evacuation disorders such as bladder emptying problems and obstructive defecation syndrome (ODS) may occur.

Moreover uterine prolapse can be caused by elongated cardinal and utero-sacral ligaments. Cystocele can be the result of failed tension of both cardinal ligaments and arcustendineus fascia pelvis support. Failed utero-sacral ligaments may cause 'posterior fornix syndrome' (fecal urgency, pelvic pain, nicturia, rectal evacuation disorders). Finally, failed perineal body can cause rectocele and can contribute to Descending Perineum Syndrome.

\section{POP and faecal incontinence}

Faecal incontinence (FI) may occur simultaneously with POP. It is estimated that $7-31 \%$ of women with POP also report having faecal incontinence [9]. On the other hand, POP occurs in $2 \%$ of women with FI who are older than 40 years [10]. Faecal incontinence and pelvic organ prolapse sometimes coexist because they share common risk factors, such as neuropathic and muscular injury to the pelvic floor after vaginal delivery and the effects of ageing [11]. Descending perineum syndrome is the proctologic disease with the strongest association between FI and POP: $92.1 \%$ of women with descending perineum have some sign of genital descent and there is a significant correlation between the Jorge incontinence score and the degree of genital relaxation $\left(r_{s} 0.85, \mathrm{P}<0.001\right)[12]$. About $50 \%$ of patients with rectal prolapse also experience FI [13] and $38 \%$ of patients have concomitant POP: the pathophysiology is surely related to weakness of the whole pelvic floor which affects both the urogenital and proctologic compartments.

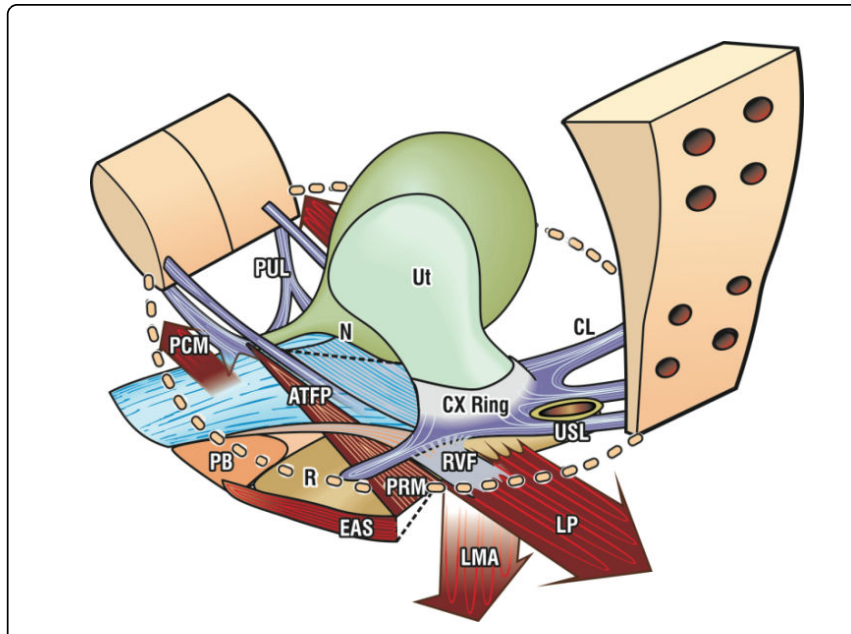

Figure 1: Integral theory view of pelvis from above and behind (Arrows: muscle forces; Ligaments: ATFP: Arcustendineus Fascia Pelvis; CL: Cardinal Ligament; USL: Uterosacral Ligament; PUL: PuboUrethral Ligament; PB: Perineal Body; LP: Levator Plate; LMA: Longitudinal Muscle of Anus; PCM: Anterior PuboCoccygus Muscle; PRM: PuboRectalis Muscle; Circular broken lines: pelvic brim; Ut: Uterus; R: Rectum; Cx: Cervical ring; N: Stretch receptor at bladder base ; EAS: Extra Anal Sphincter).

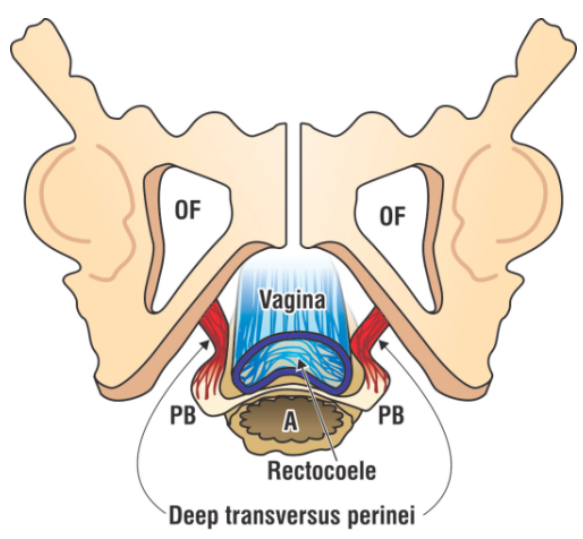

Figure 2: Pathogenesis of rectocele (Perineal Body (PB) components including Deep Transverse Perineal Muscles (DTP) are stretched laterally. The anus (A) and rectum protrude into the vagina; OF: Obturator Fossa; Surgery: TFS tape penetrates DTP and approximates the separated $\mathrm{PB}$ entities to form a neo central tendon to reduce rectocele and descending perineal syndrome).

\section{POP and obstructed defecation}

Obstructed defecation (OD) is frequently reported in women with POP. It is estimated that $18-25 \%$ of women with pelvic organ prolapse report obstructed defecation $[14,15]$, whereas about $32 \%$ of women with OD also experience POP [16]. The pathophysiological mechanisms of coexistence of the OD-POP are essentially unknown: there is no defined or significant association between any single OD symptom and POP type, nor between any OD ano-rectal cause and 
POP [17]. Thus the crux of the matter can be defined with the following three questions:

Does posterior vaginal compartment anatomy correlate with anorectal function?

Does restoring the anatomy of the posterior vaginal compartment improve defecatory function?

What is the best surgical approach to restoration of posterior vaginal compartment anatomy and defecatory function?

Other than those proposed by the Integral Theory, there are no answers to these three questions. However, some suggestions seem to link OD and POP. Breaks of the recto-vaginal septum are the main organic lesions to be found in patients affected by rectocele (posterior vaginal compartment prolapse) [18], but it is just as true that many patients with small rectoceles $(<2 \mathrm{~cm})$ are asymptomatic. There are similar considerations regarding rectal intussusception: derangement of utero- sacral ligaments (as occurs in uterine prolapse) is the etiologic factor that starts recto-rectal intussusception by weakening the recto-vaginal septum [19]. Recto-rectal intussusception may also be related to pelvic floor dyssynergia that sometimes induces impaired rectal wall contractions. In this way, if the combination of POP, rectal intussusception and pelvic floor dyssynergia is present, what is the role of each in inducing OD? Since restoring the patient's anatomy does not always improve defecatory function, it is impossible to suggest the best surgical approach for the simultaneous correction of OD and POP.

\section{Clinical evaluation of POP}

It is recognized throughout the patients with pelvic organ prolapse benefit from a multidisciplinary evaluation focusing on colorectal, gynaecologic and urologic care.

The first step of a diagnostic workup is a detailed history and physical examination of these patients, as it is imperative to identify all causative elements. Yet, physical examination, while important, is quite poor for identification of many common pelvic floor problems [20].

The other steps of evaluation pathway are represented by: scoring systems, imaging evaluation (endoanal US, dynamic cystocolpoproctography (DCP), dynamic MRI) and functional testing (ano-rectal manometry, pudendal nerve terminal motor latency testing and ano-rectal electromyography).

\section{Scoring systems}

There is no universally accepted anamnestic-clinical method for evaluating a pelvic organ prolapse (POP). Even the definition of POP is not agreed upon as previously underlined. This lack of agreement influences the anamnestic-clinical evaluation, since it is not known whether it should be limited to the urogenital district or include the posterior pelvi-perineal area. A useful validated questionnaire is the Australian Pelvic Floor Questionnaire, which evaluates prolapse symptoms (5 items), bladder function (15 items), bowel function (12 items) and sexual function (9 items) [21]. Prolapse symptoms correlate significantly with pelvic organ prolapse quantification (POP-Q) and the questionnaire can be used for routine clinical assessment and outcome research. Conversely, the Pelvic Floor Impact Questionnaire (PFIQ-7) [22], Pelvic Floor Distress Inventory (PFDI-20) [22] and Pelvic Organ Prolapse/Urinary Incontinence Sexual Questionnaire (PISQ-12) [23] are useful psychometric instruments which provide a critical assessment of the quality of life in women affected by POP
[Level of Evidence (LE): 1; Grade of Recommendation (GR): B)]. Novel scoring system [the three axial pelvic evaluation (TAPE) score] using a software program has recently been presented [24]: it expressed faecal, urinary and gynaecological functions as a geometric polygon based on symptom-specific questions where differences in overall geometric area vary from normal. The TAPE score, as presented by the Authors, may be used to define the impact of symptom-specific treatments on the pelvic floor [Level of Evidence (LE): 1; Grade of Recommendation (GR): B)]

An objective POP evaluation should offer a practical and easy method for evaluating the perineal area and detecting all POP grades. Surely the best method for providing an overall and complete study is that proposed by POP quantification (POP-Q) [25] [Level of Evidence (LE): 1; Grade of Recommendation (GR): A)] Site-specific measurements and POP stages are easily obtained with this system that is independent of examiner experience after a brief period of instruction and orientation. The POP-Q system attempts to overcome perceived deficiencies of the Baden and Walker system [26] because POP-Q attempts to measure in standard units (centimetres) the location of six vaginal sites rather than relying on relatively vague designations (e.g., "normal", "halfway to", "halfway past", or "maximum descent") that are subject to variable interpretations by different examiners. However the POP-Q itself has been questioned recently, in that it is not useful for detection of recto-anal intussusception or rectal prolapse.

\section{Imaging}

Different types of imaging may be used and imaging is based essentially on:

\section{Ultrasound evaluation (US)}

Fluoroscopy (voiding cysto-urethrography, defecography, cystoproctography, cysto-colpo-defecography)

\section{DynamicMRI}

The most diffuse imaging modality of pelvic floor is doubtless the ultrasound evaluation.

Different types of ultrasound may be used with a recognized utility [27] [Level of Evidence (LE): 1; Grade of Recommendation (GR): A)]

Transperineal ultrasonography (TPUS-called also trans-labial ultrasound or perineal ultrasound)

\section{Transvaginal ultrasonography (TVS)}

\section{Endoanalultrasonography (EAUS)}

The utility of ultrasound imaging is not only recognition of the pelvicvisceral diseases (cystocele, rectocele or enterocele, uterine prolapsed, anal sphincter defects), but also recognition of underlying aetiology. It is possible to diagnose [28] damage, avulsion defects, and abnormal contractility oflevatorani such as apathologically enlarged levator hiatus (ballooning). Moreover TPUS and TVS can detect urethral mobility, urethral vascularity, funneling of the internal urethral meatus, bladder neck descent and bladder wall thickness. EAUS is the gold standard to assess anal sphincter integrity [Level of Evidence (LE): 1; Grade of Recommendation (GR): A)].

For many years the strong point of fluoroscopy has been the evaluation of POP in the more physiologic standing or seated positions. Conversely, the more invasive nature of fluoroscopic studies, which require organ opacification for visualization, the inability to 
simultaneously evaluate all three pelvic compartments and the use of ionizing radiation are the disadvantages of this type of examination. Fluoroscopy assessments are [29]: voiding cysto-urethrography (VCUG), with or without urodynamic testing; evacuation proctography or defecography; cysto-proctography and cysto-colpoproctography. VCUG studies the wholebladder position (e.g. Cystocele), evaluates the bladder neck in relationship to the pubic symphysis, the urethro-vesical junction's mobility, the presence of bladder and urethra-diverticula and finally vescico-vaginal or urethrovaginal fistulas. Evacuation Proctography (also called defecography) is indicated when there is suspicions of rectal intussusception, rectal prolapse, rectocele or pelvic floor dyssynergia. To have a global view of pelvic content, the defecography can be combined with bladder evaluation (cysto-proctography) and/or vaginal study (cysto-colpoproctography). Dynamic colpocysto-defecography provides direct visualization and quantification of female pelvic organ prolapse but dynamic magnetic resonance [29] imaging offers a perfect image of what is happening in women affected by pelvic organ prolapse. The whole pelvic district with urethra, bladder, uterus, vagina, rectum, anal canal, pelviperineal muscles, perineal body and supportive elements of the endopelvic fascia, is easily seen at rest and dynamically, during squeezing, straining, defecation, or urination.

The disadvantages of dynamic MRI are the high cost, the need for specialist radiological interpretation and the absence of seated position if not available. The use of dynamic MRI should be indicated in patients with multi-compartment disease, posterior compartment abnormalities, severe prolapse, or recurrent symptoms after surgical repair.

A combined protocol of 3D ultrasonography and dynamic pelvic MRI can be recommended for pre- and post-operative evaluation [Level of Evidence (LE): 3B; Grade of Recommendation (GR): C)].

\section{Functional tests}

Anorectal-manometry is useful for accurate definition of anal canal pressures, recto-anal inhibitory reflex, rectal sensations and rectal compliance. All these parameters are used for functional evaluation of obstructed defecation and faecal incontinence. Anorectal-manometry is a useful tool in ano-rectal disorders combined with POP but alone it does not provide sufficient grounds for the diagnosis [Level of Evidence (LE): 3B; Grade of Recommendation (GR): C)].

Another functional evaluation is the anal neurophysiological testing. External anal sphincter electromyography, motor-evoked potentials, somatosensory evoked potentials and sacral anal reflex latency measurement are currently available to evaluate neurogenic anorectal disorders [Level of Evidence (LE): 2A; Grade of Recommendation (GR): B)]. Diagnosis of pudendal nerve damage, nerve which supplies voluntary control of external anal sphincter, may be reached and prolongation of electrical impulse across this nerve may have impacts on evacuative control [30]. Finally, anal electromyography may be useful in patients with obstructed defecation. It senses electrical activity during rest, squeeze, and strain and can be useful to identify patients with paradoxical contraction of the puborectalis, sign of pelvic floor dyssynergia.

\section{The uro-gynaecological evaluation}

Stress urinary incontinence is the most common dysfunction in uro-gynaecologic clinical practice in up to $72 \%$ of patient presenting for the first time evaluation. While some degree of POP is seen in the
$61 \%$ of patients at first uro-gynaecologic evaluation, it is not always symptomatic. Other common dysfunctions are detrusor over-activity (13\% and $40 \%$ of patients), bladder oversensitivity (10-13\% of patients) and voiding dysfunctions [31,32]. The uro-gynaecological point of view on pelvic floor dysfunctions (PFD) is essentially focused on the dysfunctions of the anterior and central pelvic floor's compartments, whatever considered as expression of a generalized pelvic floor disease.

\section{History and Clinical Evaluation}

The first steps that must be considered to diagnose any type of urinary incontinence (UI) are history taking and clinical evaluation. On examining a woman that suffers from UI, ideally with a full bladder, it is possible see an involuntary loss of urine on coughing. If the involuntary urine leakage is synchronous with the efforts of the patients, e.g. on sneezing or coughing, it can be diagnosed as stress urinary incontinence. One must also think of urgency UI if the patient also has a compelling desire to void that is difficult to defer. A cotton swab test can be useful to identify bladder neck hypermobility [33].

One needs to systematically search for anomalies of the vulva (e.g. cysts, infections, tumors, atrophic changes), of the urethra (e.g. mucosal prolapse, urethral caruncle and diverticulum) as well as vagina. The vaginal length and mobility, presence of scarring, pain, and estrogenic mucosal influence need to be evaluated. Presence of POP must be noted and a scoring system must be used.

Examination of the pelvic floor includes a search for perineal scars and evaluation of muscle function which is classified as normal active, overactive, underactive and non-functioning. Pubo-rectalis muscle must be evaluated to search for avulsion injury.

\section{Investigations}

Different types of questionnaires to assess urinary symptoms and QOL can be used to stratify the gravity of UI and the discomfort of these patient, but until now there is no evidence that the use of questionnaires has any impact on outcomes of treatment [Level of Evidence (LE): 3; Grade of Recommendation (GR): B)]. Voiding diaries can be used as semi-objective method for symptom quantification [Level of Evidence (LE): 3; Grade of Recommendation (GR): B)].

In patients with UI, different types of urodynamic studies can be performed: uroflowmetry, post-void residual volume (urine volume), cystometry, filling cystometry (that allows the assessment of bladder sensation, bladder capacity, detrusor activity, and bladder compliance) and voiding cystometry.

However there is a poor correlation between UI symptoms and urodynamic findings.

Imaging of uro-gynaecological diseases is based on ultrasound techniques: the advent of 3D trans-perineal and trans-vaginal ultrasound has increased the knowledge of pelvic floor anatomy and dysfunctions of the pelvic floor [27,34-36].

\section{Conservative treatment}

Asymptomatic POP does not require any treatment. The initial therapeutic work-up of POP, when women with symptomatic prolapse might decline surgical management, is conservative treatment [37]. Two main nonsurgical treatment options are pessary placement and 
Page 5 of 10

pelvic floor muscle exercises. Of course, these options can be used simultaneously or individually.

The primary goal of pessary management is to prevent the pelvic organs from bulging beyond the opening of the vagina, thereby alleviating prolapse symptoms. Pessaries can provide immediate relief of prolapse symptoms and can be appropriate for either temporary or long-term use [38]. [Level of Evidence (LE): 1; Grade of Recommendation (GR): A)]. Pessary management provides visible results as early as 1 year of follow-up when the patient experiences significant improvement in the stage of disease $(\mathrm{P}=0.045$, Wilcoxon signed rank test) and have no worsening in stage of prolapsed [Level of Evidence (LE): 5; Grade of Recommendation (GR): C)]. However, it should be emphasized that there is no literature published on pessary usage in the single POP type.

Pelvic floor muscle training (PFMT) is used clinically to treat prolapse, but there is little empirical evidence available regarding its effectiveness [39]. There are possible biases regarding PFMT due to the absence of a universally accepted exercises protocol and to lack of sustained patient compliance regarding the exercise programs. There are many trials that support a significant success rate in both anatomical and symptomatic aspects [40]. The evaluation of PFMT effects on urinary and fecal incontinence is different because the longterm success rate is well defined in both diseases (67\% [41] and 53\% [42], respectively). The International Consultation on Incontinence recommends pelvic floor muscle training as the first-line treatment for stress, urge, or mixed incontinence in women of all ages [43]. The American Society of Colon and Rectal Surgeons suggests that rehabilitative treatment may be considered a first-line option for many patients with faecal incontinence who have not responded to simple dietary modification or medication [44]. Also obstructed defecation is initially treated by conservative management and rehabilitative treatment. After rehabilitation, some patients become symptom free and many have an improved obstructed defecation score [45]. The long-term success rate is approximately $50 \%$ [Level of Evidence (LE): 1; Grade of Recommendation (GR): A)] [46,47].

\section{Surgical treatment of POP}

The primary objective of pelvic organ prolapse surgery is to improve symptoms. Concomitant urinary, bowel, and sexual dysfunction symptoms must be addressed prior to surgery and the risks and postoperative expectations should be discussed [48]. Surgery for pelvic organ prolapse can be approached vaginally, abdominally, laparoscopically, robotically, and even a combination of these (Table 1).

\begin{tabular}{|l|l|}
\hline Type of intervention & Indication \\
\hline $\begin{array}{l}\text { Vaginal hysterectomy with uterosacral } \\
\text { ligament }\end{array}$ & Posterior compartment prolapse \\
\hline Posterior native tissue colporraphy & Posterior compartment prolapse \\
\hline Abdominal sacrocolpopexy & Post-hysterectomy apical prolapsed \\
\hline $\begin{array}{l}\text { Anterior colporraphy with or without } \\
\text { synthetic graft }\end{array}$ & Anterior compartment prolapsed \\
\hline Repair of the apex & Apical prolapse \\
\hline $\begin{array}{l}\text { Uterosacral ligament suspension with } \\
\text { transvaginal or abdominal approach }\end{array}$ & Vault prolapse (post-hysterectomy) \\
\hline $\begin{array}{l}\text { Sacrospinous ligament } \\
\text { suspension }\end{array}$ & Vault prolapse \\
\hline
\end{tabular}

\begin{tabular}{|l|l|}
\hline $\begin{array}{l}\text { Colpocleisis with or without } \\
\text { perineorraphy }\end{array}$ & Vaginal prolapse \\
\hline Sacrocolpopexy with or without mesh & $\begin{array}{l}\text { Apical compartments disorders } \\
\text { associated or not with rectocele, } \\
\text { enterocele, complete rectal prolapsed }\end{array}$ \\
\hline Rectopexy & Internal or external rectal prolapsed \\
\hline
\end{tabular}

Table 1: Surgical treatment.

Vaginal hysterectomy with utero-sacral suspension may be performed for uterine prolapse; posterior native tissue colporrhaphy is the most common for posterior compartment prolapse and posthysterectomy apical prolapse is repaired with abdominal sacrocolpopexy.

Anterior colporrhaphy is the most common procedure for anterior compartment prolapse with or without the use of synthetic graft; Anterior native tissuecolporrhaphy implies the midline plication of the attenuated pubo-cervical fascia. Studies have shown high recurrence rates, up to $50 \%$ andcurrent evidence does not clearly support this approach to anterior compartment repair [49-53] [Level of Evidence (LE): 3; Grade of Recommendation (GR): C)]. Longer attempts to reduce high failure rates in the anterior compartment have lead to the use of graft material. The graft material most commonly in use is synthetic polypropylene mesh [54,55] [Level of Evidence (LE): 2A; Grade of Recommendation (GR): B)]. The posterior compartment is more successfully repaired with native tissue colporrhaphy than the anterior compartment, with cure rates in the order of $80 \%$. Traditional midline fascial plication compares favourably with site-specific repair. The use of graft in the posterior compartment for primary prolapse is not supported by current evidence [56-58] [Level of Evidence (LE): 1A; Grade of Recommendation (GR): A)]. The apex consists of the uterus and cervix, or vault in the post-hysterectomy patient, and the upper vagina. Apical prolapse rarely occurs in isolation, and repair of the apex is often combined with repair of one or both of the other compartments. Apical prolapse repairs can be performed vaginally or abdominally, with or without the uterus in situ [58] [Level of Evidence (LE): 1A; Grade of Recommendation (GR): A)].

Transvaginalutero-sacral ligament suspension can be performed either as an intra-peritoneal or extra-peritoneal vaginal procedure. The vaginal intra-peritoneal approach consists in placing permanent and/or delayed absorbable sutures into the intra-peritoneal middle third of the utero-sacral ligament bilaterally and passing each end of these sutures through the proximal transverse edge of the pubocervical and recto-vaginal fasciae, thereby recreating the peri-cervical ring. A meta-analysis of transvaginalutero-sacral ligament suspension reported successful apical outcome in $98 \%$, with median follow-up of 25 months [59] [Level of Evidence (LE): 1A; Grade of Recommendation (GR): A)]. Extra-peritonealuterosacral ligament suspension is a useful approach for post-hysterectomy vault prolapse as it does not require entry into the peritoneal cavity and has less risk of ureteric injury than intraperitoneal procedure [60] [Level of Evidence (LE): 3B; Grade of Recommendation (GR): C)]. It can be performed through an anterior or posterior approach. Success for the vaginal cuff is reported at $95 \%$ at 2 years, with recurrent anterior compartment prolapse in 9.2\% [61] [Level of Evidence (LE): 4; Grade of Recommendation (GR): C)]. The McCall culdoplasty is performed at the time of vaginal hysterectomy and involves the placement of 1-3 'internal' (intraperitoneal) sutures from one utero-sacral ligament to the other incorporating the peritoneum of the cul-de-sac, the aim of 
which is to obliterate the cul-de-sac to prevent formation of an enterocele. A further series of 'external' sutures anchors the distal utero-sacral ligament pedicles to the vaginal vault [62] [Level of Evidence (LE): 3B; Grade of Recommendation (GR): C)].

Sacrospinous ligament vault suspension can be performed at the time of vaginal hysterectomy or for post-hysterectomy vault prolapse. Unilateral or bilateral sutures are placed into the sacrospinous ligament and attached to the vaginal vault [63] [Level of Evidence (LE): 3B; Grade of Recommendation (GR): B)]. If the prolapse is predominantly apical with the uterus in situ, a discussion with the patient regarding the options of uterine-sparing prolapse repair versus hysterectomy and vault suspension is required. The decision to retain the uterus is made in the absence of uterine or cervical pathology. If future fertility is not an issue, the Manchester repair with cervical amputation, shortening of the utero-sacral ligament with re-attachment to the anterior cervixis also an option. If pregnancies are desired, then the abdominal approach with attachment of polypropylene mesh between vagina cervix and anterior sacrum (abdomino-sacrohysteropexy) or vaginally with a sacrospinous-hysteropexy can be performed. The mesh delivery systems for apical prolapse repair involve fixation of the mesh to the sacro-spinous ligament using a variety of kit-specific techniques and can be used with or without uterine preservation; success rates at 1 year is reported at 82 and $86 \%$, respectively [64] [Level of Evidence (LE): 2B; Grade of Recommendation (GR): C)]. Colpocleisis is an obliterative vaginal prolapse procedure traditionally performed on non-sexually active women with existing medical co-morbidities which preclude them from having more extensive prolapse surgery. The procedure can be partial or complete and involves denudation of the anterior and posterior vaginal walls, with imbrication of the fascia and suturing of the distal edges of the anterior and posterior mucosal edges together. It is often performed with an aggressive perineorrhaphy to provide extra support [65] [Level of Evidence (LE): 2A; Grade of Recommendation (GR): B)]. Abdominal utero-sacral ligament suspension re-attaches the uterosacral ligament to the vaginal vault or cervix. A number of different techniques have been described, but all involve the passage of sutures through the middle third of the uterosacral ligament suspension, which are then attached to the vault or cervix [66] [Level of Evidence (LE): 4; Grade of Recommendation (GR): C)]. Short-term results are encouraging with $88 \%$ success at 1 year, but no long-term data regarding durability are available.

Sacrocolpopexy and rectopexy are procedures frequently performed to correct POPs disorders. Sacrocolpopexy is a procedure more familiar for the gynecologists; it is considered the choice's treatment for [67].

Apical compartment disorders in associations or not with others concomitant defects as rectocele, enterocele or complete rectal prolapse.

Apical defects in young woman and patient who wish to remain sexually active.

These procedures are associated with good outcomes in term of postoperative satisfaction and quality of life by the patients with good long term outcomes [Level of Evidence (LE): 2A; Grade of Recommendation (GR): B)] [68,69].

Sacrocolpopexy procedures aim to suspend the vaginal apex to the anterior longitudinal ligament of the sacrum using synthetic mesh or biologic mesh as xenografts (porcine dermis or bovine tissues) and allografts (cadaveric fascia) meshes to correct apical and/or advanced anterior wall prolapse [70]. Both open (Abdominal Sacrocolpopexy -
ASP) and mini invasive approach (video-laparoscopic or robotic assisted sacrocolpopexy- LSP and RCP) are validated procedures.

The rate of recurrence after ASP range from $0 \%$ to $22 \%[67,68]$ [Level of Evidence (LE): 2A; Grade of Recommendation (GR): B)]. Despite a longer operation time, longer recovery and potential mesh complications, when compared to sacrospinous ligament fixation(SSLF) and utero-sacral ligament suspension (USLS), ASP has greater durability, lower rate of recurrence of vault prolapse and less dyspareunia compared with vaginal sacrospinous colpopexy [71] [Level of Evidence (LE): 1A; Grade of Recommendation (GR): A)].

Concerning to the type of mesh used for ASP, when compared to the synthetic mesh, xenograft mesh has greater probability of operation failure [Level of Evidence (LE): 1B; Grade of Recommendation (GR): A)]. According to Culligan and coworkers, cadaveric fascia (allograft mesh) has a greater incidence of prolapse at one year after the operation than polypropylene mesh [Level of Evidence (LE): 1B; Grade of Recommendation (GR): A)] [72]. An important complication linked with polypropylene mesh use is erosion, with a risk that ranges from $3.4 \%$ to $10.5 \%$ after ASP; polyester mesh use is associated with an increased risk of mesh erosion [Level of Evidence (LE): 1B; Grade of Recommendation (GR): A)] [73].

Mini invasive approach, both laparoscopic and robotic assisted rectopexy, compared to the ASP, allows a lower blood loss during the operation, a quicker recovery, less pain and a shorter hospital stay [Level of Evidence (LE): 1A; Grade of Recommendation (GR): A)].

Robotic Sacrocolpopexy has a longer operation time and it is more expensive than laparoscopic Sacrocolpopexy and ASP71 but the last review of Cochrane showed no decisive outcomesbetween the two techniques [71] [Level of Evidence (LE): 1A; Grade of Recommendation (GR): A)].

During surgery to correct vaginal prolapse, it is possible to perform a "prophylactic" procedure to prevent correlated symptoms of urinary incontinence, obstructed defecation as well as of sexual dysfunction. In a study by Brubaker et al. a multicenter randomized controlled trial of prophylactic Burch retropubic-urethropexy at the time of ASC, the patients after Burch urethropexy showed significantly decreased risk of SUI in the post-operative period [74] [Level of Evidence (LE): 1B; Grade of Recommendation (GR): A)].

The same consideration must be taken when a rectocele is present: concomitant correction of rectocele may improve the symptoms of obstructed defecation [Level of Evidence (LE): 1B; Grade of Recommendation (GR): A)] [71].

Rectopexy is the abdominal procedure indicated in young or healthy patients with external rectal prolapse or with internal rectal prolapse that becomes symptomatic [Level of Evidence (LE): 5; Grade of Recommendation (GR): D)].

The rectopexy consists essentially in mobilization and fixation of the rectum. Rectal fixation to the sacral promontory can be performed with suture or mesh with an anterior (ventral) or posterior approach associated or not to a sigmoid resection [75].

A Cochrane review of 12 randomized or quasi-randomized clinical trial with 380 patients indicated that these procedures do not show better outcomes for one treatment over another [Level of Evidence (LE): 1A; Grade of Recommendation (GR): A)] [76]. Recurrence rate after abdominal rectum mobilization-only (open or laparoscopic) seem not differ with others types of procedures (both mobilization-pexy or 
mobilization-resection-pexy with abdominal or laparoscopic approach) and this procedure has a recurrence rate of $28.9 \%$ at 10 years of $\mathrm{FU}$ [77] [Level of Evidence (LE): 2B; Grade of Recommendation (GR): B)].

Also, the division of lateral rectum ligaments after the rectum mobilization prior to sacral fixation is correlated with a lower recurrence rate. In according with Bordeianou L et al. [75], patients with complete rectal prolapse who suffer from constipation are candidates for a sigmoid resection; if present, a rectocele or enterocele must be evaluated as to whether to perform a sacrocolpopexy or a ventral rectopexy with mesh [Level of Evidence (LE): 5; Grade of Recommendation (GR): D)].

Limitations of mini invasive approach are the absence of threedimensional vision and the impossibility of assessing the level of tension for the pelvic organ re-suspension. The use of laparoscopic 3D vision or of the robotic surgery can help to overcame these problems, but the high cost, the longer operation time associated with the specialized equipment of robotic surgery have reduced the widespread of this approach [Level of Evidence (LE): 3B; Grade of Recommendation (GR): B)] [78]. To date there is not sufficient evidence to utilize robotic surgery for this type of procedure [75].

Up to now the question if the pexies are the gold standard techniques for any POP repair has no answer. Unfortunately there isn't enough evidence concerning procedures with prostheses due to the small number of participants, inadequacy of randomization or inclusion criteria. Moreover, the presence of multiple different surgical techniques and materials has made it difficult to achieve evidencebased data on long term outcome.

\section{POP repair and FDA warning}

There has been a FDA warning about prostheses use in POP surgical treatment. Despite this FDA report, the use of prostheses remains high as it is still considered an excellent and appropriate option of treatment of pelvic prolapse.

Although there aren't shared recommendations on the use of meshes, some suggestions are the following [Level of Evidence (LE): 3; Grade of Recommendation (GR): C)]: before using meshes it is fundamental to inform patients on risks, benefits, surgical and nonsurgical alternatives [79-82]; the routine use of biological material is not advisable as it seem to have no real benefit [83-85]; heavier weight prostheses are reported to shrink more often than lower weight ones [85];

In vaginal surgery macroporous monofilament polypropylene should be the choice while polyester prostheses frequently have been linked to erosion complications [85]; new products must not be assumed to have an equal or improved safety and efficacy until long term data are available [79]; it is of paramount importance to continue to collect follow-up data, with the aim of reviewing long term outcomes [79];

A common complication after prosthetic surgery for pelvic organ prolapse is the presence of an erosion or exposure, which happens when the prosthesis is visualized through the vaginal mucosa. This is different from an extrusion which is the gradual passage of mesh out of the epithelium. In the literature, the average rate of erosions after vaginal surgery is about $10 \%$, ranging from 5 to $19 \%$, while it is reported in about $3 \%$ of patients after laparotomic sacro-colpopexies and in $2 \%$ with a laparoscopic procedure [80-82]. Other adverse events are the presence of vaginal or pelvic pain (4-11\%), dyspareunia (1-3\%), rectal injuries $(<0.5 \%)[86,87]$.

There is not any way to avoid complications and in almost all papers, the experience of the surgeon is directly linked to the safety and efficacy of the procedure, and inversely linked to incidence of adverse events [Level of Evidence (LE): 4; Grade of Recommendation (GR): B)]; the use of a macroporous polypropylene monofilament mesh is recommended in vaginal prosthetic surgery. It is better to avoid the use of a polyester meshes [Level of Evidence (LE): 4; Grade of Recommendation (GR): B)].

Medical therapy with estrogen before and after surgery has not been demonstrated to improve outcome;[B]. Often, de novo symptoms such as vaginal and pelvic pain, spotting, dyspareunia, voiding dysfunctions will usually disappear six weeks after surgery. Thus, many of the commonest complications can be initially managed with observation and medical therapy (non-steroidal anti-inflammatory medications, trigger point injections, pelvic floor muscle physical therapy, and vaginal dilators) until a surgical treatment is required. Even an uncomplicated mesh erosion, when $<5 \mathrm{~mm}$, can be initially treated without surgery. If the conservative therapy fails or if the erosion is associated with other symptoms, patients will undergo surgery.

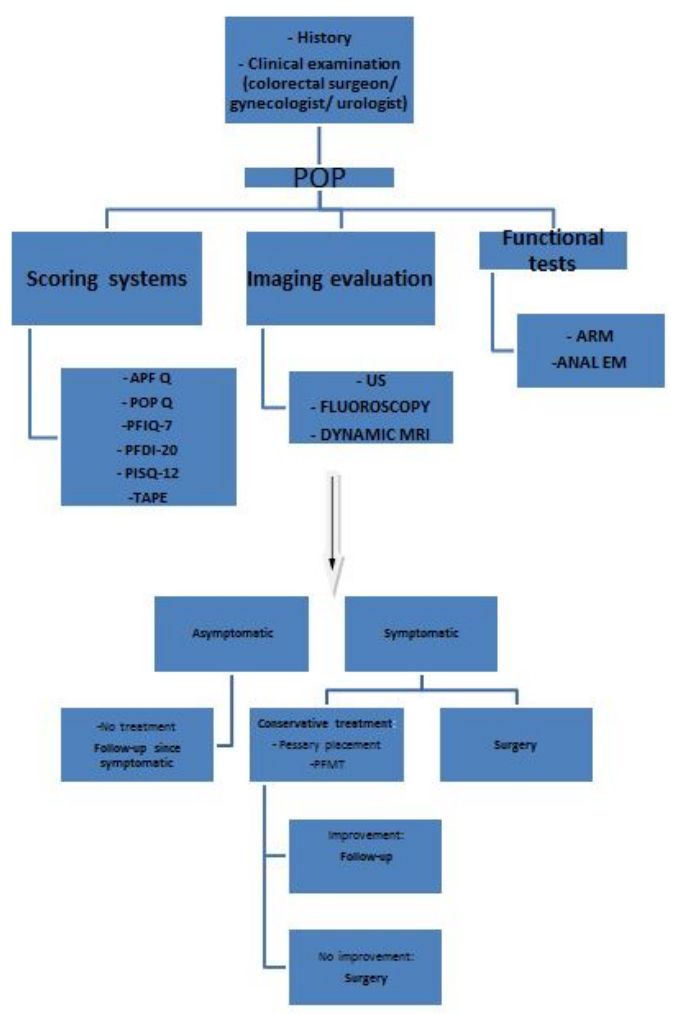

Figure 3: Diagnosis and management of POP flow-chart (POP: pelvic organ prolapse; US: Ultrasound; MRI: Magnetic Resonance Imaging; ARM: AnoRectal Manometry; ANAL EM: Electromiography; PFMT: Pelvic Floor Muscles Training).

The surgical options are a partial excision as an office procedure of a small exposure $<5 \mathrm{~mm}$ or in the operating room when $>5 \mathrm{~mm}$. Moreover, the removal of a great portion of the prosthesis is indicated if a previous treatment has failed or in presence of an infection or 
fistula. Trans-vaginal excision of the prosthesis is less invasive than the abdominal route; another severe complication is the shrinkage/ contraction of the vaginal mesh which can lead to the presence of localized areas of tension or contraction band or a stricture of the vagina. The treatment can require a simple section or full excision of the contracted area being in tension, with or without excision of the mesh. Unfortunately, even if the excision often improves symptoms, it is not always effective. In patients with voiding dysfunction the simple transaction of the sling without excision of the mesh usually improves symptoms. [Level of Evidence (LE): 4; Grade of Recommendation (GR): C)] (Figure 3).

Expert panel recommendation. Surgery for POP often requires an interdisciplinary team and mesh (non-absorbable) insertion carries a high risk of erosion and complications [Level of Evidence (LE): 2; Grade of Recommendation (GR): B)].

\section{References}

1. Oxford Centre for Evidence-Based Medicine 2011 Levels of Evidence.

2. Schaffer JI, Wai CY, Boreham MK (2005) Etiology of pelvic organ prolapse. Clin Obstet Gynecol 48: 639-647.

3. Jelovsek JE, Maher C, Barber MD (2007) Pelvic organ prolapse. Lancet 369: 1027-1038.

4. Strinic T, Vulic M, Tomic S, Capkun V, Stipic I, et al. (2009) Matrix metalloproteinases-1,-2 expression in uterosacral ligaments from women with pelvic organ prolapse. Maturitas 64: 132-135.

5. Chen B, Yeh J (2011) Alterations in Connective Tissue Metabolism in Stress Incontinence and Prolapse. J Urol 186: 1768-1772.

6. Ward RM, Velez Edwards DR, Edwards T, Giri A, Jerome RN, et al. (2014) Genetic epidemiology of pelvic organ prolapse: a systematic review. Am J Obstet Gynecol 211: 326-335.

7. Petros, Papa PE (2010) The Female Pelvic Floor, Function, Dysfunction and Management According to the Integral Theory. Springer Heidelberg 3rd edition 118-218.

8. Wagenlehner FM, Del Amo E, Santoro G, Petros P (2013) Perineal body repair in patients with 3 rd degree rectocele. A critical analysis of the tissue fixation system. Colorectal Dis 15: e760-e765.

9. Yavagal S, de Farias TF, Medina CA, Takacs P (2011) Normal Vulvovaginal, Perineal, and Pelvic Anatomy with reconstructive Considerations. Semin Plast Surg 25: 121-129.

10. Rortveit G, Subak LL, Thom DH, Creasman JM, Vittinghoff E, et al (2010) Urinary incontinence, fecal incontinence and pelvic organ prolapse in a population-based racially diverse cohort: prevalence and risk factors. Female Pelvic Med Reconstr Surg 16: 278-283.

11. RC Bump, PA Norton (1998) Epidemiology and natural history of pelvic floor dysfunction. Obstet Gynecol Clin North Am 25: 723-746.

12. Pucciani F, Boni D, Perna F, Bassotti G, Bellini M (2005) Descending perineum syndrome: are abdominal hysterectomy and bowel habits linked? Dis Colon Rectum 48: 2094-2099.

13. Bordeianou L, Rockwood T, Baxter N, Lowry A, Mellgren A, et al. (2008) Does incontinence severity correlate with quality of life? Prospective analysis of 502 consecutive patients. Colorectal Dis 10: 273-279.

14. Bradley CS, Brown MB, Cundiff GW, Goode PS, Kenton KS, et al. (2006) Pelvic Floor Disorders Network. Bowel symptoms in women planning surgery for pelvic organ prolapse. Am J Obstet Gynecol 195: 1814-1819.

15. Whitcomb EL, Lukacz ES, Lawrence JM, Nager CW, Luber KM (2009) Prevalence of defecatory dysfunction in women with and without pelvic floor disorders. Female Pelvic Med Reconstr Surg 15:179-187.

16. Pucciani F, Raggioli M, Ringressi MN (2012) Obstructed defecation: what is the role of rehabilitation? Colorectal Dis 14: 474-479.

17. Grimes CL, Lukacz ES (2012) Posterior vaginal compartment prolapse and defecatory dysfunction: are they related? Int Urogynecol J 23: 537-551.
18. DeLancey JO (1999) Structural anatomy of the posterior pelvic compartment as it relates to rectocele. Am J Obstet Gynecol 180: 815-823.

19. Abendstein B, Petros P (2008) Role of the uterosacral ligaments in the causation of rectal intussusception, abnormal bowel emptying, and fecal incontinence. A prospective study. Pelviperineology 27: 118-121.

20. McNevin MS (2010) Overview of pelvic floor disorders. Surg Clin North Am 90: 195-205.

21. Baessler K, O'Neill SM, Maher CF, Battistutta D (2010) A validated selfadministered female pelvic floor questionnaire. Int Urogynecol J 21: 163-172.

22. Barber MD, Walters MD, Bump RC (2005) Short forms of two conditionspecific quality-of-life questionnaires for women with pelvic floor disorders (PFDI-20 and PFIQ-7). Am J Obstet Gynecol 193: 103-113.

23. Rogers RG, Coates KW, Kammerer-Doak D, Khalsa S, Qualls CA (2003) Short form of the Pelvic Organ Prolapse Urinary Incontinence Sexual Questionnaire (PISQ-12). Int Urogynecol J Pelvic Floor Dysfunct 14: 164-168.

24. Altomare DF, Di Lena M, Giuratrabocchetta S, Giannini I, Falagario M, et al. (2014) The Three Axial Perineal Evaluation (TAPE) score: a new scoring system for comprehensive evaluation of pelvic floor function. Colorectal Dis 16: 459-468.

25. Bump RC, Mattiasson A, Bo K, Brubaker L, DeLancey JOL, et al. (1996) The standardization of terminology of female pelvic organ prolapse and pelvic floor dysfunction. Am J Obstet Gynaecol 175: 10-7.

26. Baden WF, Walker TA (1972) Statistical evaluation of vaginal relaxation. Clin Obstet Gynecol 15: 1070-1072.

27. Santoro GA, Wieczorek AP, Dietz HP, Mellgren A, Sultan AH, et al. (2011) State of the art: an integrated approach to pelvic floor ultrasonography. Ultrasound Obstet Gynecol 37: 381-396.

28. Woodfield CA, Krishnamoorthy S, Hampton BS, BrodyJM (2010) Imaging Pelvic Floor Disorders: Trend Toward Comprehensive MRI. AJR Am J Roentgenol 194: 1640-1649.

29. Ricciardi R, Mellgren AF, Madoff RD, et al. (2006) The utility of pudendal nerve terminal motor latencies in idiopathic incontinence. Dis Colon Rectum 49: 852-857.

30. Farouk El Sayed R (2013) The urogynecological side of pelvic floor MRI: the clinician's needs and the radiologist's role. Abdom Imaging 38: 912-929.

31. Lucas MG, Bedretdinova D, Bosch JLHR, Burkhard F, Cruz F. et al. (2014) E A U Guidelines on Urinary Incontinence.

32. McCarthy TA (1991) Medical history and physical examination. In: Ostergard DR, Bent AE (eds) Urogynecology and urodynamics: theory and practice, 3rd edn. Baltimore: Williams \& Wilkins, pp 99-101.

33. Santoro GA, Wieczorek AP, Stankiewicz A, Wozniak MM, Bogusiewicz $M$, et al. (2009) High-resolution three dimensional endovaginal ultrasonography in the assessment of pelvic floor anatomy: a preliminary study. Int Urogynecol J 20: 1213-1222.

34. Dietz HP, Steensma AB (2005) Posterior compartment prolapse on twodimensional and three-dimensional pelvic floor ultrasound: the distinction between true rectocele, perineal hypermobility and enterocele. Ultrasound Obstet Gynecol 26: 73-77.

35. Dietz HP (2010) Pelvic floor ultrasound: a review. Am J ObstetGynecol 202: 321-334.

36. Culligan PJ (2012) Nonsurgical management of pelvic organ prolapse. Obstet Gynecol 119: 852-860.

37. Handa VL, Jones M (2002) Do pessaries prevent the progression of pelvic organ prolapse? Int Urogynecol J Pelvic Floor Dysfunct 13: 349-351.

38. Burgio KL (2014) Pelvic floor muscle training for pelvic organ prolapse. Lancet 383: 760-762.

39. Shobeiri SA, Santiago AC (2014) Randomised controlled trial. Individualised pelvic floor muscle training is an effective conservative treatment in women with pelvic organ prolapsed. Evid Based Med 19: 213.

40. Dumoulin C, Hay-Smith J, Habée-Séguin GM, Mercier J (2014) Pelvic floor muscle training versus no treatment, or inactive control treatments, 
for urinary incontinence in women: A short version Cochrane systematic review with meta-analysis. Neurourol Urodyn.

41. Heymen S, Scarlett Y, Jones K, Ringel Y, Drossman D, et al. (2009) Randomized controlled trial shows biofeedback to be superior to pelvic floor exercises for fecal incontinence. Dis Colon Rectum 52: 1730-1737.

42. Moore K, Dumoulin C, Bradley C (2013) Adult conservative management. In:P Abrams, L Cardozo, S Khoury, A Wein (Eds.) Incontinence, 5th International Consultation on Incontinence, Health Publications, Plymbridge 1101-1127.

43. Tjandra JJ, Dykes SL, Kumar RR, Ellis CN, Gregorcyk SG, et al. (2007) and the Standards Practice Task Force of The American Society of Colon and Rectal Surgeons Practice Parameters for the Treatment of Fecal Incontinence. Dis Colon Rectum 50: 1497-1507.

44. Chiarioni G, Whitehead WE, Pezza V, Morelli A, Bassotti G (2006) Biofeedback is superior to laxatives for normal transit constipation due to pelvic floor dyssynergia. Gastroenterology 130: 657-664.

45. Rao SS, Seaton K, Miller M, Brown K, Nygaard I, et al. (2007) Randomized controlled trial of biofeedback, sham feedback, and standard therapy for dyssynergic defecation. Clin Gastroenterol Hepatol 5: 331-338.

46. Aponte MM, Rosenblum N (2014) Repair of pelvic organ prolapse: what is the goal? Curr Urol Rep 15: 385.

47. Dwyer PL, O'Reilly BA (2004) Transvaginal repair of anterior and posterior compartment prolapse with Atrium polypropylene mesh. BJOG 111: 831-836

48. Demirci F, Ozdemir I, Somunkiran A, Gul OK, Gul B, et al. (2007) Abdominal paravaginal defect repair in the treatment of paravaginal defect and urodynamic stress incontinence. J Obstet Gynaecol 27: 601-604.

49. Shippey SH, Quiroz LH, Sanses TV, Knoepp LR, Cundiff GW, et al. (2010) Anatomic outcomes of abdominal sacrocolpopexy with or without paravaginal repair. Int Urogynecol J 21: 279-283.

50. Viana R, Colaco J, Vieira A, Goncalves V, Retto H (2006) Cystocelevaginal approach to repairing paravaginal fascial defects. Int Urogynecol J Pelvic Floor Dysfunct 17: 621-623.

51. Morse AN, O’Dell KK, Howard AE, Baker SP, Aronson MP, et al. (2007) Midline anterior repair alone vs anterior repair plus vaginal paravaginal repair: a comparison of anatomic and quality of life outcomes. Int Urogynecol J Pelvic Floor Dysfunct 18: 245-249.

52. Dwyer P (2006) Evolution of biological and synthetic grafts in reconstructive pelvic surgery. Int Urogynecol J 17:10-15.

53. Moore RD, Beyer RD, Jacoby K, Freedman SJ, McCammon KA, et al. (2010) Prospective multicenter trial assessing type I, polypropylene mesh placed via transobturator route for the treatment of anterior vaginal prolapse with 2-year follow-up. Int Urogynecol J 21: 545-552.

54. Cundiff GW, Fenner D (2004) Evaluation and treatment of women with rectocele: focus on associated defecatory and sexual dysfunction. Obstet Gynecol 104: 1403-1421.

55. Paraiso MF, Barber MD, Muir TW, Walters MD (2006) Rectocele repair: a randomized trial of three surgical techniques including graft augmentation. Am J Obstet Gynecol 195: 1762-1771.

56. Murphy M (2008) Clinical practice guidelines on vaginal graft use from the society of gynecologic surgeons. Obstet Gynecol 112: 1123-1130.

57. Margulies RU, Rogers MA, Morgan DM (2010) Outcomes of transvaginal uterosacral ligament suspension: systematic review and metaanalysis. Am J Obstet Gynecol 202: 124-134.

58. Dwyer PL, Fatton B (2008) Bilateral extraperitoneal uterosacral suspension: a new approach to correct posthysterectomy vaginal vault prolapse. Int Urogynecol J Pelvic Floor Dysfunct 19: 283-292.

59. Fatton B, Dwyer PL, Achtari C, Tan PK (2009) Bilateral extraperitoneal uterosacral vaginal vault suspension: a 2-year followup longitudinal case series of 123 patients. Int Urogynecol J Pelvic Floor Dysfunct 20: 427-434.

60. McCall M (1957) Posterior culdeplasty; surgical correction of enterocele during vaginal hysterectomy: a preliminary report. Obstet Gynecol 10: 595-602.
61. Richter K, Albrich W (1981) Long-term results following fixation of the vagina on the sacrospinal ligament by the vaginal route (vaginaefixatio sacrospinalis vaginalis). Am J Obste Gynecol 141: 811-816.

62. Elmer C, Altman D, Engh ME, Axelsen S, Vayrynen T, et al. (2009) Trocar-guided transvaginal mesh repair of pelvic organ prolapse. Obstet Gynecol 113:117-126.

63. Abbasy S, Kenton K (2010) Obliterative procedures for pelvic organ prolapse. Clin Obstet Gynecol 53: 86-98.

64. Lowenstein L, Fitz A, Kenton K, FitzGerald MP, Mueller ER, et al. (2009) Transabdominaluterosacral suspension: outcomes and complications. Am J Obstet Gynecol 200: 656 e1-656 e5.

65. Siddiqui NY, Edenfield AL (2014) Clinical challenges in the management of vaginal prolapse. Int J Womens Health 6: 83-94.

66. Crisp CC, Book NM, Smith AL, Cunkelman JA, Mishan V, et al. (2013) Body image, regret, and satisfaction following colpocleisis. Am J Obstet Gynecol 209: 473.e1-7.

67. Fitzgerald MP, Richter HE, Bradley CS, Ye W, Visco AC, et al. (2008) Pelvic support, pelvic symptoms, and patient satisfaction after colpocleisis. Int Urogynecol J Pelvic Floor Dysfunct 19: 1603-1609.

68. Feiner B, Jelovsek JE, Maher C (2009) Efficacy and safety of transvaginal mesh kits in the treatment of prolapse of the vaginal apex: a systematic review. BJOG 116: 15-24.

69. Culligan PJ, Blackwell L, Goldsmith LJ, Graham CA, Rogers A, et al. (2005) A randomized controlled trial comparing fascia lata and synthetic mesh for sacral colpopexy. Obstet Gynecol 106: 29-37.

70. Cundiff GW, Varner E, Visco AG, Zyczynski HM, Nager CW, et al. (2008) Risk factors for mesh/suture erosion following sacral colpopexy. Am J Obstet Gynecol 199: 688e1-e5.

71. Brubaker L, Cundiff GW, Fine P, Nygaard I, Richter HE, et al. (2006) Abdominal sacrocolpopexy with Burch colposuspension to reduce urinary stress incontinence. N Engl J Med 354: 1557-1566.

72. Bordeianou L, Hicks CW, Kaiser AM, Alavi K, Sudan R, et al. (2014) Rectal Prolapse: an overview of clinical features, diagnosis, and patientspecific management strategies. J Gastrointest Surg 18: 1059-1069.

73. Tou S, Brown SR, Malik AI, Nelson RL (2008) Surgery for complete rectal prolapse in adults. Cochrane Database Syst Rev 8: CD001758.

74. Raftopoulos Y, Senagore AJ, Di Giuro G, Bergamaschi R (2005) Rectal Prolapse Recurrence Study Group. Recurrence rates after abdominal surgery for complete rectal prolapse: a multicenter pooled analysis of 643 individual patient data. Dis Colon Rectum 48: 1200-1206.

75. Heemskerk J, de Hoog DE, van Gemert WG, Baeten CG, Greve JW, et al. (2007) Robot-assisted vs. conventional laparoscopic rectopexy for rectal prolapse: a comparative study on costs and time. Dis Colon Rectum; 50: 1825-1830.

76. Ellington DR, Richter HE (2013) Indications, contraindications, and complications of mesh in surgical treatmentofpelvic organ prolapse. Clin Obstet Gynecol 56: 276-288.

77. Van Geelen JM, Dwyer PL (2013) Where to for pelvic organ prolapse treatment after the FDA pronouncements? A systematic review of the recent literature. Int Urogynecol J 24: 707-718.

78. Mucowski SJ, Jurnalov C, Phelps JY (2010) Use of vaginal mesh in the face of recent FDA warnings and litigation. Am J Obstet Gynecol 203: 103.e1-103.e4.

79. Patel BN, Lucioni A, Kobashi KC (2012) Anterior pelvic organ prolapse repair using syntheticmesh. Curr Urol Rep 13: 211-215.

80. Cox A, Herschorn S (2012) Evaluation of current biologic meshes in pelvic organ prolapse repair. Curr Urol Rep 13: 247-255.

81. Yurteri-Kaplan LA, Gutman RE (2012) The use of biological materials in urogynecologic reconstruction: asystematicreview. Plast Reconstr Surg 130: 242S-253S.

82. Mercer-Jones MA, D'Hoore A, Dixon AR, Lehur P, Lindsey I, et al. (2014) Consensus on ventral rectopexy: report of a panel of experts. Colorectal Dis 16: $82-88$

83. Barber MD (2013) Surgical techniques for removing problematic mesh. Clin Obstet Gynecol 56: 289-302. 
Citation: Torre FI, Pucciani F, Dodi G, Giuliani G, Frasson A, et al. (2017) Pelvic Organ Prolapse (POP) Working Group (SICCR): Doubts and Evidence for a Practical Guide. J Inflam Bowel Dis \& Disord 2: 115.

Page 10 of 10

84. Chermansky CJ, Winters JC (2012) Complications of vaginal mesh surgery. Curr Opin Urol 22: 287-291.

85. Deffieux X, Letouzey V, Savary D, Sentilhes L, Agostini A, et al. (2012) Prevention of complications related to the use of prosthetic meshes in prolapsed surgery: guidelines for clinical practice. Eur J Obstet Gynecol Reprod Biol 165: 170-180.

86. Ellington DR, Richter HE (2013) The role of vaginal mesh procedures in pelvic organ prolapse surgery in view of complication risk. Obstet Gynecol Int 2013: 356960.
87. Hammett J, Peters A, Trowbridge E, Hullfish K (2014) Short-term surgical outcomes and characteristics of patients with mesh complications from pelvic organ prolapse and stress urinary incontinence surgery. Int Urogynecol J 25: 465-470. 